\title{
Aplicaciones del láser en Odontología
}

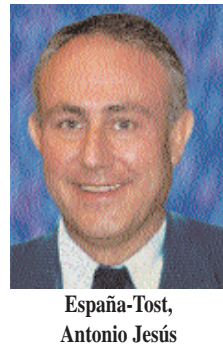

\section{Laser applications in dentistry}

\section{España-Tost, Antonio Jesús* \\ Arnabat-Domínguez, José* \\ Berini-Aytés, Leonardo** \\ Gay-Escoda, Cosme***}

*Médico Estomatólogo. Profesor Asociado de Cirugía Bucal y Profesor del Máster de Cirugía Bucal e Implantología Bucofacial. Facultad de Odontología de la Universidad de Barcelona. **Médico Estomatólogo. Cirujano Maxilofacial. Profesor Titular de Patología Quirúrgica Bucal y Maxilofacial. Profesor del Máster de Cirugía Bucal e Implantología Bucofacial. Facultad de Odontología de la Universidad de Barcelona.

*** Médico Estomatólogo. Cirujano Maxilofacial. Catedrático de Patología Quirúrgica Bucal y Maxilofacial. Director del Máster de Cirugía Bucal e Implantología Bucofacial. Facultad de Odontología de la Universidad de Barcelona. Cirujano Maxilofacial del Centro Médico Teknon.

\section{Correspondencia}

Cosme Gay Escoda

Centro Médico Teknon

C/ Vilana 12

08022 Barcelona

E-mail: cgay@ub.edu

Website: http://www.gayescoda.com
Resumen: Existen diferentes tipos de láseres que pueden tener aplicación en Odontología, y éstos pueden ser utilizados con diferentes fines. El propósito de este artículo es comentar, de forma genérica, el empleo de diferentes tipos de láseres en diversos tipos de tratamientos habituales en la práctica odontológica.

No todos los láseres producen los mismos efectos; tampoco un mismo láser produce el mismo efecto sobre diferentes tejidos, y, según sean los parámetros de emisión utilizados, incluso el mismo láser puede producir diferentes efectos sobre el mismo tejido.

Para poder incorporar el láser a la praxis diaria, el profesional debe conocer, entre otros extremos, las indicaciones, las contraindicaciones y la forma de utilización del tipo o tipos de láseres que desee utilizar, antes de su aplicación en clínica.

Palabras clave: Láser en Odontología, Láser de Er, Cr:YSGG, Láser de Er:YAG, Láser de CO2, Láser de Diodo, Láser de Nd:YAG, Láser de alta potencia, Láser quirúrgico.

Abstract:There are several different lasers that can be used in dentistry, and they can also be applied for different purposes. The aim of the present report is to comment in general terms on applications of different kinds of lasers in the wide range of dental treatments.

Not all the lasers produce the same effects, neither does the same laser on different tissues, and depending on the emission parameter settings, also the same laser can provide different effects on the same tissue.

Before introducing a laser device into the office, the clinician should be aware of the indications, contraindications and usage of the specific type of laser to be used before applying it clinically.

Key words: Laser dentistry, Er,Cr:YSGG laser, Er:YAG laser, CO2 laser, Diode laser, Nd:YAG laser, High power laser, Surgical laser.

\begin{tabular}{ccc}
\hline Fecha recepción & Fecha última revisión & Fecha aceptación \\
$25-4-2000$ & $26-2-2001$ & $19-3-2001$ \\
\hline
\end{tabular}

BIBLID [1138-123X (2004)9:5; septiembre-octubre 477-612]

España-Tost AJ, Arnabat-Domínguez J, Berini-Aytés L, Gay-Escoda C. Aplicaciones del láser en Odontología. RCOE 2004;9(5):497-511. 


\section{Introducción}

La aplicación del láser en Odontología debe basarse en el conocimiento de una serie de procesos físicos y biológicos que dependen de diversos factores. Cada tipo de láser emite energía luminosa con una única longitud de onda; es, por tanto, una luz monocromática. En función de la longitud de onda del láser y dónde se aplique se podrán producir diferentes fenómenos ópticos. La luz láser, al igual que la luz visible, cumple todos los principios básicos de la óptica: transmisión, reflexión, refracción y absorción. La energía lumínica que producirá el o los efectos sobre los tejidos irradiados será aquella que sea absorbida, es decir, aquella que libere su energía.

Los fenómenos de absorción dependen básicamente de dos factores: la longitud de onda del láser y las características ópticas del tejido que debe ser irradiado.

La cavidad bucal contiene tejidos muy distintos entre sí; por tanto las características ópticas de los tejidos que la conforman no van a tener el mismo comportamiento cuando sean irradiadas con la misma longitud de onda. Es decir, podríamos necesitar una longitud de onda diferente para cada uno de los tejidos que hay en la cavidad bucal. Cuando con el mismo láser irradiamos dos tejidos diferentes, los efectos que se producen también serán diferentes.

De igual modo, cuando aplicamos diferentes longitudes de onda sobre el mismo tejido, el comportamiento de la luz tampoco va a ser igual. Es decir, diferentes láseres producen efectos distintos sobre el mismo tejido.

Hay que tener en cuenta que cada láser solo va a emitir en una única longitud de onda y que por lo tanto podremos obtener diferentes efectos sobre los tejidos tratados.

Las unidades emisoras de energía láser permiten variar algunos parámetros relativos a la cantidad de energía liberada por unidad de tiempo, o lo que es lo mismo, la potencia. Las piezas de mano que nos van a facilitar el transporte de la energía hasta el tejido diana suelen ir provistas de una óptica que nos permitirá, en función de la distancia de aplicación, concentrar o repartir la energía láser en una menor o mayor superficie de aplicación. Así pues, cuando estamos aplicando una determinada cantidad de energía por unidad de tiempo, en una superficie pequeña obtenemos mayor densidad de potencia que cuando la aplicamos a una superficie mayor. La densidad de potencia determinará diferentes efectos sobre el mismo tejido.

Para entender los procesos ópticos que rigen el comportamiento de los láseres es necesario introducirse en el conocimiento de la Física. No es la intención de este artículo explicar cómo se producen, sino tan sólo comentar las aplicaciones de dichos procesos en los tratamientos odontológicos más habituales.

\section{Clasificación de los láseres}

Los láseres son susceptibles de ser clasificados de múltiples formas. Pueden clasificarse en relación a su medio activo, según sea su longitud de onda, forma de emisión u otros criterios, pero quizás la forma más habitual de clasifi- carlos es atendiendo a la potencia a la cual van a ser usados. Así pues, es frecuente referirse a dos grandes grupos de láseres:

- Láser de baja potencia.

- Láser de alta potencia.

Los láseres de baja potencia son aquellos que van a ser utilizados, principalmente, por su acción bioestimulante, analgésica y antiinflamatoria.

Los láseres de alta potencia serán aquellos que producen efectos físicos visibles, y que se emplean como sustitutos del bisturí frío o del instrumental rotatorio convencional.

Si bien en la bibliografía existen descripciones sobre más de un millar de láseres distintos, en la práctica sólo unos pocos están comercializados y disponibles para su uso clínico.

Los láseres de baja potencia más conocidos son:

- As, Ga (Arseniuro de Galio)

- As,Ga,Al (Arseniuro de Galio y Aluminio)

- He,Ne (Helio-Neon)

Los láseres de alta potencia disponibles en el mercado odontológico son:

- Argon

- Diodo

- Nd:YAG

- Nd:YAP

- Ho:YAG

- Er,Cr:YSGG

- Er:YAG

- $\mathrm{CO}_{2}$

Cada uno de ellos posee características propias que lo hacen diferente a los demás. En algunas ocasiones un mismo tratamiento se podría efectuar con más de un tipo de láser, aunque siempre hay alguno que puede ofrecer mejores características que los demás para aquel tratamiento en concreto.

Las características de cada uno de 
estos láseres, así como sus indicaciones más relevantes, serán tratadas de forma individualizada en el resto de artículos que componen este monográfico sobre el láser aplicado en Odontología.

De los láseres de alta potencia citados anteriormente, algunos son más empleados que otros. Por ejemplo, el láser de Argon es poco utilizado. Sus indicaciones estarían limitadas al tratamiento quirúrgico de lesiones vasculares, si bien se ha descrito su utilización en otros procedimientos. Existen algunas variedades del láser de Argon que son sustitutos de la lámpara halógena, con las mismas indicaciones que ésta: fotopolimerización y blanqueamiento. Es el único láser de alta potencia, de los previamente referidos, que emite luz visible. Todos los demás emiten luz infrarroja.

El láser de Nd:YAP tiene las mismas indicaciones que el láser de Nd:YAG. A pesar de tener diferente longitud de onda, tienen comportamientos muy parecidos.

El láser de Ho:YAG proviene de los antiguos países del Este, y en la actualidad no está demasiado introducido en el área odontológica.

Así pues, de los láseres nombrados, los más relevantes son los de Diodo, $\mathrm{Nd}$ YYAG, Er:YAG, Er,Cr:YSGG y CO 2, y nos referiremos a ellos para describir las principales indicaciones de los láseres de alta potencia en Odontología.

Es frecuente que la información que nos llega a través de las casas comerciales sea confusa. El elevado coste de las unidades emisoras de energía láser obliga, en cierta forma, a que el fabricante intente justificar su uso en un gran número de procedimientos muy diferentes. La mayoría de las veces se incluyen tratamientos donde el uso de

\begin{tabular}{|cc|}
\hline \multicolumn{2}{|c|}{ Tabla 1. Efecto que se produce en los tejidos, } \\
& según la temperatura alcanzada \\
\hline Temperatura & Efecto tisular \\
\hline $42-45^{\circ} \mathrm{C}$ & Hipertermia transitoria \\
\hline$>65^{\circ} \mathrm{C}$ & Desecación, desnaturalización proteica \\
\hline $70-90^{\circ} \mathrm{C}$ & Coagulación y fusión tisular \\
\hline$>100^{\circ} \mathrm{C}$ & Vaporización \\
\hline$>200^{\circ} \mathrm{C}$ & Carbonización \\
\hline
\end{tabular}

aquel láser es ampliamente superado por otros, y es que en la cavidad bucal existen demasiadas variantes histológicas como para que con un único láser podamos cubrir todas las necesidades de tratamiento. No obstante existen láseres más versátiles que otros, y algunos de ellos, a pesar de no ser los ideales para aquel tratamiento, pueden ser usados si el profesional conoce las limitaciones de los mismos.

\section{Indicaciones de los láseres de alta potencia}

Antes de abordar los diferentes aspectos de la utilización de los láseres de alta potencia en los distintos tratamientos odontológicos, hay que recordar que existen unas normas de seguridad, muy estrictas, en el manejo de este tipo de láseres, que deben ser conocidas y puestas en práctica tanto por el profesional responsable de su utilización como por su equipo de colaboradores.

Los láseres a los que haremos refe- rencia emiten luz no visible al ojo humano, con longitudes de onda situadas en el espectro infrarrojo. La interacción de estas longitudes de onda con los tejidos produce un efecto fototérmico, más o menos importante. Así pues, el principio de utilización de todos ellos está basado en este efecto fototérmico. No obstante, ya que se trata de diferentes longitudes de onda, no siempre van a ser absorbidos de igual forma, produciendo una amplia gama de efectos relacionados con su absorción.

Según la temperatura que adquiera el tejido diana, se pueden producir diferentes efectos, tal como podemos observar en la tabla 1, pudiendo variar desde una hipertermia transitoria hasta la carbonización del mismo.

Los láseres mejor absorbidos producen un rápido incremento de la temperatura en la zona de aplicación. Por ejemplo, el láser de $\mathrm{CO}_{2}$ es muy bien absorbido por los tejidos blandos, produciendo incrementos de temperatura cercanos a los $1700^{\circ} \mathrm{C}$ en el punto de aplicación. No obstante, produce menor calentamiento de los tejidos adyacentes que otros láseres peor absorbidos en superficie. El láser de Diodo y el láser de Nd:YAG no son bien absorbidos por los tejidos blandos, con el riesgo de que se produzca un acúmulo térmico en los 
tejidos adyacentes, que en caso de que superara los $65^{\circ} \mathrm{C}$ produciría la necrosis de los mismos.

El efecto térmico acumulado de-penderá del tiempo de aplicación. Hay láseres que emiten en modo continuo y láseres que emiten en modo pulsado. Dado que el incremento térmico acumulado depende del tiempo de aplicación, el usuario de la unidad emisora debe conocer estos aspectos para evitar producir efectos iatrogénicos derivados de un mal uso del láser.

Tanto el láser de Er,Cr:YSGG como el de Er:YAG son muy bien absorbidos por el agua. Se trata de láseres que se emiten en modo pulsado, y que aprovechan esta máxima absorción por el agua para producir su acción. Son los más indicados para la eliminación de tejidos duros, y cuando son utilizados con spray de aire y agua no producen efecto térmico en los tejidos irradiados. En estos láseres la utilización del spray de agua, además de proteger a los tejidos adyacentes al evitar el efecto térmico, favorece su mecanismo de acción.

A continuación abordaremos la mayoría de tratamientos odontológicos en los que se puede utilizar algún tipo de láser, y valoraremos su pertinencia, tanto desde el punto de vista de nuestra experiencia personal, que puede resultar subjetiva, como desde el punto de vista de la evidencia científica publicada en la literatura.

\section{Terapéutica Dental}

\section{Preparación de cavidades}

En la actualidad se aconseja la utilización de los láseres de Er,Cr:YSGG y de Er:YAG como sustitutos de la turbi$\mathrm{na}^{1}$. Se recomienda emplearlos con spray de aire y agua, para minimizar e efecto térmico. El aumento de temperatura que se produce en la cámara pulpar es inferior a los $4^{\circ} \mathrm{C}$, por lo que su uso no representa ningún riesgo $0^{2,3}$. La zona irradiada queda libre de barrillo dentinario; por este motivo no es necesario grabar la dentina si se utiliza un sistema adhesivo basado en el «grabado total». El esmalte queda con una rugosidad parecida a la obtenida con la aplicación del ácido ortofosfórico, evitando así su aplicación ${ }^{4}$. Se obtienen cavidades similares a las que se pueden preparar con el instrumental rotatorio convencional. Existen discrepancias en relación con las fuerzas de adhesión obtenidas cuando se acondiciona el esmalte con láseres de Er:YAG o de Er,Cr:YSGG. Para la mayoría de autores, se obtendrían fuerzas de adhesión menores, pero al superar el $70 \%$ de resultado obtenido con el ácido ortofosfórico, se podrían considerar una alternativa aceptable ${ }^{5}$.

El tiempo invertido en la preparación de una cavidad, con los láseres de Er,Cr:YSGG o de Er:YAG, suele ser mayor que el utilizado con la turbina convencional ${ }^{1}$.

Se ha descrito la utilización del láser de Nd:YAG para la preparación de cavidades, pero requiere un pigmento iniciador (tinta china), y el efecto térmico que produce pone en serio peligro la vitalidad del diente.

También existen trabajos en los que se describe el uso del láser de $\mathrm{CO}_{2}$ con la finalidad de vitrificar la dentina y para conseguir un alto efecto bactericida.

Los láseres de Er,Cr:YSGG y de Er:YAG permiten la preparación de cavidades sin necesidad de utilizar técnica alguna de anestesia locorregional. Diversos estudios cifran en un $94 \%$ el porcentaje de tratamientos realizados sin la aplicación de anestesia ${ }^{6^{*}}$. Esta característica abre nuevas expectativas para el tratamiento de pacientes, que por razones diversas, no acepten o en los que no esté aconsejado el uso de anestésicos locales. Por este motivo, estos láseres son cada vez más recomendables en Odontopediatría y para el tratamiento de pacientes especiales ${ }^{7}$.

El láser de Er,Cr:YSGG, cuando se aplica a baja densidad de potencia sobre la dentina, produce un efecto desensibilizante. Esto permite alternar, si es necesario, la utilización del instrumental rotatorio convencional con el láser, todo ello sin la administración de soluciones anestésicas.

Se ha descrito la utilización del láser de $\mathrm{CO}_{2}$ para el tratamiento de las exposiciones pulpares, con la finalidad de coagular y descontaminar la zona expuesta. Se obtienen buenos resultados cuando la exposición pulpar se produce a consecuencia de un traumatismo, siempre que el tratamiento se efectúe durante las 24 primeras horas. Cuando la exposición pulpar se produce durante la eliminación de una caries las posibilidades de éxito descienden enormemente ${ }^{8 * *}$.

Existen trabajos en los que se concluye que tras la irradiación de los bordes de la cavidad con láser $\left(\mathrm{CO}_{2}\right.$, $\mathrm{Er}$, Cr:YSGG, Er:YAG y Nd:YAG), se producen cambios en la composición del esmalte, otorgándole menor solubilidad frente al ataque ácido de la placa bacteriana, y por consiguiente se obtiene mayor resistencia contra la aparición de caries secundarias ${ }^{9}$. También existen trabajos en los cuales no se encuentran estas diferencias ${ }^{10}$. 
En relación con la fuerza de adhesión entre los materiales de obturación y la dentina, cuando se ha utilizado el láser de Er:YAG en la preparación de una cavidad, existen discrepancias en cuanto a los resultados. Para unos autores disminuiría la fuerza de adhesión $^{11}$, y para otros sería una alternativa válida, al no observarse diferencias significativas ${ }^{10}$.

\section{Eliminación de obturaciones antiguas}

Las obturaciones de amalgama de plata reflejan la energía láser. Si se utiliza algún láser con este propósito, debe irradiarse sobre las zonas del diente que favorecen la retención del material de obturación, hasta conseguir su total liberación.

Los láseres más aconsejados para este fin son el de Er,Cr:YSGG y el de Er:YAG, ya que con ellos es fácil eliminar antiguas obturaciones de composite, ionómeros y silicatos.

\section{Sellado de fosas y fisuras}

Todos los láseres de alta potencia citados pueden ser utilizados o bien para preparar el esmalte previamente a la aplicación del sistema de sellado, o bien como complemento, con la finalidad de obtener un efecto bactericida ${ }^{12}$.

Los láseres más aconsejados para esta indicación son el de Er,Cr:YSGG y el de Er:YAG ${ }^{4,5}$.

\section{Hiperestesia dentinaria}

Todos los láseres nombrados anteriormente, tanto de alta potencia como de baja potencia, tienen protocolos de aplicación para el tratamiento de la hiperestesia dentinaria. Cada uno de ellos consigue eliminar la hiperestesia por mecanismos muy diversos.

\section{Endodoncia}

En el tratamiento de los conductos radiculares, el láser aporta nuevas y buenas perspectivas como complemento al tratamiento convencional.

La preparación biomecánica del conducto radicular se efectúa de forma convencional, pero existen publicaciones en las que se utilizan los láseres de Er,Cr:YSGG o de Er:YAG para dicho $\mathrm{fin}^{13}$.

Uno de los objetivos del tratamiento endodóncico es conseguir la mayor eliminación posible de los microorganismos patógenos que pudieran quedar en el diente en tratamiento. Para ello se utilizan diferentes soluciones de productos químicos, entre las cuales la más efectiva es la solución de hipoclorito sódico al $5 \%$. En este aspecto la utilización del láser de Nd:YAG parece igualar los resultados obtenidos con el hipoclorito sódico al 5\%, sin el riesgo que supondría un eventual paso de la solución de hipoclorito sódico a la zona periapical.

Se ha propuesto el uso de otros láseres para obtener la descontaminación del conducto radicular. El láser de $\mathrm{CO}_{2}$ sólo produce el efecto bactericida en los puntos donde es aplicado, ya que es notablemente absorbido en superficie. Tampoco puede ser utilizado con la facilidad del láser de Nd:YAG ya que no puede ser transmitido por fibra óptica. Los láseres de Er,Cr:YSGG y de Er:YAG sí pueden ser aplicados a través de fibra óptica, obteniéndose altos niveles de desinfección, comparables al hipoclorito sódico al $1 \%{ }^{14}$.

El láser de Diodo tiene un comportamiento más parecido al láser de Nd:YAG, y también puede aplicarse a través de fibra óptica y no es absorbido en superficie. Este hecho facilita que la luz penetre a través de la dentina consiguiendo así que su poder bactericida actúe más allá de lo que se obtiene con una irrigación con hipoclorito sódico ${ }^{15,16}$.

\section{Odontología estética}

\section{Carillas y obturaciones del frente anterior}

La preparación de los tejidos duros dentarios en Odontología estética se realiza de acuerdo con las mismas consideraciones expuestas anteriormente en el apartado de la preparación de cavidades.

Se pueden utilizar los láseres de Er,Cr:YSGG y de Er:YAG. Se han publicado algunos artículos en los que se describe la técnica de preparación de los dientes para la colocación de carillas de cerámica utilizando el láser de Er,Cr:YSGG ${ }^{17}$.

\section{Blanqueamiento dental}

La primera consideración que hay que hacer sobre esta indicación es que ningún láser produce efecto de blanqueamiento por sí mismo. Simplemente acelera los procesos de descomposición del peróxido de hidrógeno utilizado habitualmente en las técnicas de blanqueamiento dentario.

Se han propuesto diferentes láseres para este procedimiento, si bien el más utilizado es el láser de Diodo. Otros que pueden ser de interés para esta indicación son el láser de Argón, el láser de $\mathrm{Nd}$ YYAG con duplicador de frecuencia (KTP), y la combinación de láser de $\mathrm{CO}_{2}$ para calentar la mezcla y el láser de Argón para acelerar la descomposición del peróxido de hidrógeno. 
Con el empleo del láser, los tiempos de trabajo se ven reducidos respecto a la utilización de la lámpara halógena, pero el grado de blanqueamiento obtenido no supera los resultados de otros procedimientos más clásicos ${ }^{18}$.

El blanqueamiento dental con láser no aporta otra ventaja que la reducción del tiempo de tratamiento, pero sin duda se ha convertido en una buena herramienta de marketing.

\section{Prótesis}

Las indicaciones del uso del láser en cirugía preprotésica se comentarán en el apartado de Cirugía Bucal.

Preparación dentaria para la colocación de coronas

Se ha descrito la preparación de dientes para la colocación de coronas completas con el láser de Er,Cr:YSGG. En nuestra opinión, cuando sólo se utiliza el láser, no se consigue la misma precisión en los márgenes de la preparación que cuando utilizamos el instrumental rotatorio convencional. En determinadas ocasiones, especialmente cuando no se pueda utilizar anestesia local, se puede efectuar la preparación protésica del diente alternando el uso del láser con la turbina. En este caso el láser se aplica sobre la dentina, a baja densidad de potencia, con el propósito de desensibilizar el diente ${ }^{19}$.

\section{Cirugía Bucal}

En el Máster de Cirugía Bucal e Implantología Bucofacial de la Universidad de Barcelona disponemos de diversos láseres para su utilización en pro- cedimientos quirúrgicos, pero sin duda con el que más experiencia hemos acumulado es con el láser de $\mathrm{CO}_{2}$. Otros láseres como el de Er:YAG o el de Er,Cr:YSGG, debido a su escaso efecto térmico, los estamos empleando en algunos procedimientos, como sustitutos o complemento al instrumental rotatorio convencional, ac-tuando sobre los tejidos duros dentarios y sobre el hue$\mathrm{so}^{20}$. Otros láseres de alta potencia como el láser de Diodo, los utilizamos como complemento en aquellas intervenciones quirúrgicas en las que precisamos mejor desinfección de la zona en tratamiento, como por ejemplo en la cirugía periapical y en ciertos procedimientos de cirugía periodontal. Otros láseres más clásicos, como el de Nd:YAG o el láser de Argón, tienen indicaciones muy limitadas en la especialidad de Cirugía Bucal, y la tendencia general es la de usar láseres que puedan tener aplicaciones en un amplio abanico de patologías de tejidos blandos y duros de la cavidad oral.

Desde la incorporación a la práctica clínica del láser de Er:YAG, y más recientemente del láser de Er,Cr:YSGG podemos efectuar algunas intervenciones quirúrgicas poco invasivas sin necesidad de aplicar soluciones anestésicas (fig. 1).

En la extracción quirúrgica de dientes incluidos, la cirugía periapical u otras intervenciones en las que se hace una incisión para poder elevar, posteriormente, un colgajo mucoperióstico, si bien se ha descrito el uso de diferentes láseres como sustitutos del bisturí, en nuestra experiencia resulta más precisa la incisión con la lámina fría convencional. El bisturí actúa de forma selectiva corta los tejidos blandos y no afecta a los tejidos duros; en cambio el láser, cuando finaliza el corte de los tejidos blandos, puede seguir irradiando el hueso subyacente, con el riesgo que esto puede implicar según el láser que estemos utilizando.

Cuando sea preciso eliminar o cortar hueso, los láseres que pueden ser utilizados son el de Er,Cr:YSGG y el de Er:YAG. Existen citas que aconsejan el uso preferente de estos láseres en lugar de los sistemas rotatorios convencionales ya que la reparación ósea tras la actuación quirúrgica se produce de una forma más rápida, apreciándose una menor respuesta inflamatoria en los tejidos manipulados ${ }^{21}$.

Tras la extracción quirúrgica de los terceros molares incluidos se puede observar un curso postoperatorio más favorable con menor edema y dolor cuando se ha efectuado todo el procedimiento quirúrgico con el láser de Er,Cr:YSGG.

En los tratamientos combinados ortodóncico-quirúrgicos de los dientes incluidos se puede colocar el bracket de forma intraoperatoria, acondicionando el esmalte dentario con los láseres de Er,Cr:YSGG o de Er:YAG. De esta forma evitamos la necesidad de emplear el gel de ácido ortofosfórico dentro del campo operatorio, anulando así el riesgo que pueda suponer éste si se desparrama por los tejidos adyacentes.

En la cirugía periapical puede utilizarse más de un láser simultáneamente: los láseres de Er,Cr:YSGG o de Er:YAG para los tejidos duros y los láseres de Nd:YAG o de Diodo para eliminar, en lo posible, los microorganismos patógenos que puedan existir tanto en la zona periapical como en el propio diente. También se puede utilizar el láser de baja potencia para disminuir los síntomas y signos postoperatorios ${ }^{22}$. 

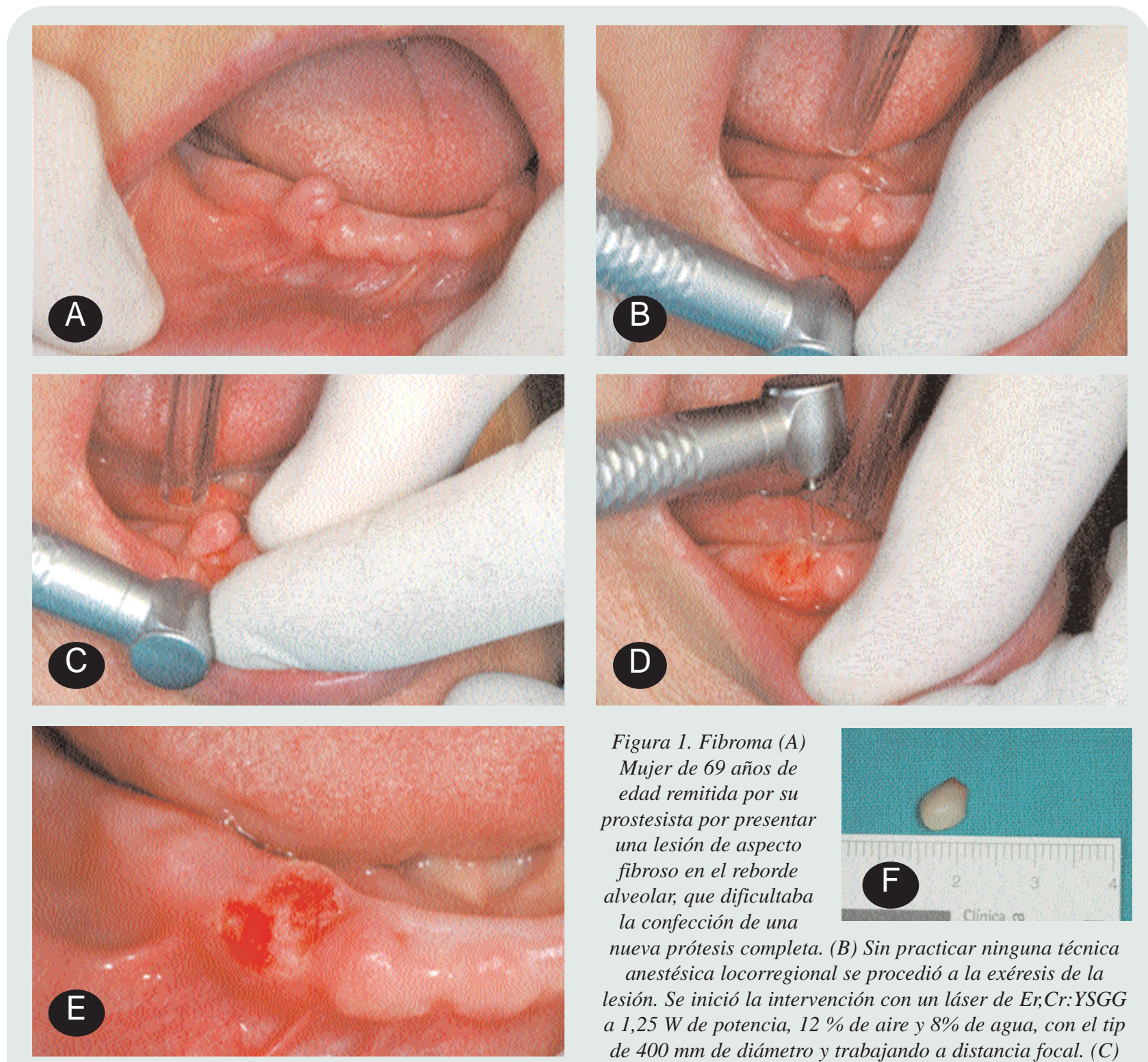

Figura 1. Fibroma (A) Mujer de 69 años de edad remitida por su prostesista por presentar una lesión de aspecto fibroso en el reborde alveolar, que dificultaba la confección de una

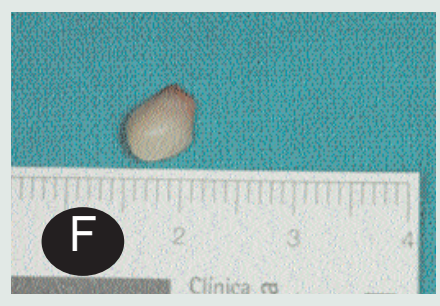
nueva prótesis completa. (B) Sin practicar ninguna técnica anestésica locorregional se procedió a la exéresis de la lesión. Se inició la intervención con un láser de Er,Cr:YSGG a 1,25 W de potencia, $12 \%$ de aire y $8 \%$ de agua, con el tip de $400 \mathrm{~mm}$ de diámetro y trabajando a distancia focal. (C) Los impactos del láser iban dirigidos a la base de la lesión, rodeándola. (D) Una vez completada la exéresis se procedió a regularizar el lecho quirúrgico y controlar la hemostasia. Para ello se seleccionó $1 \mathrm{~W}$ de potencia, $6 \%$ de aire y $4 \%$ de agua, aplicando la energía de forma ligeramente desfocalizada. (E) Aspecto del postoperatorio inmediato. (F) La muestra fue remitida al servicio de Anatomía Patológica para su estudio. El diagnóstico histológico fue de hiperplasia fibrosa, corroborando así nuestro diagnóstico de presunción. (G) No se prescribió ningún tipo de fármaco ni colutorio. El postoperatorio cursó sin ningún tipo de molestia para la paciente. La imagen corresponde a las cuatro semanas después de la intervención quirúrgica. 

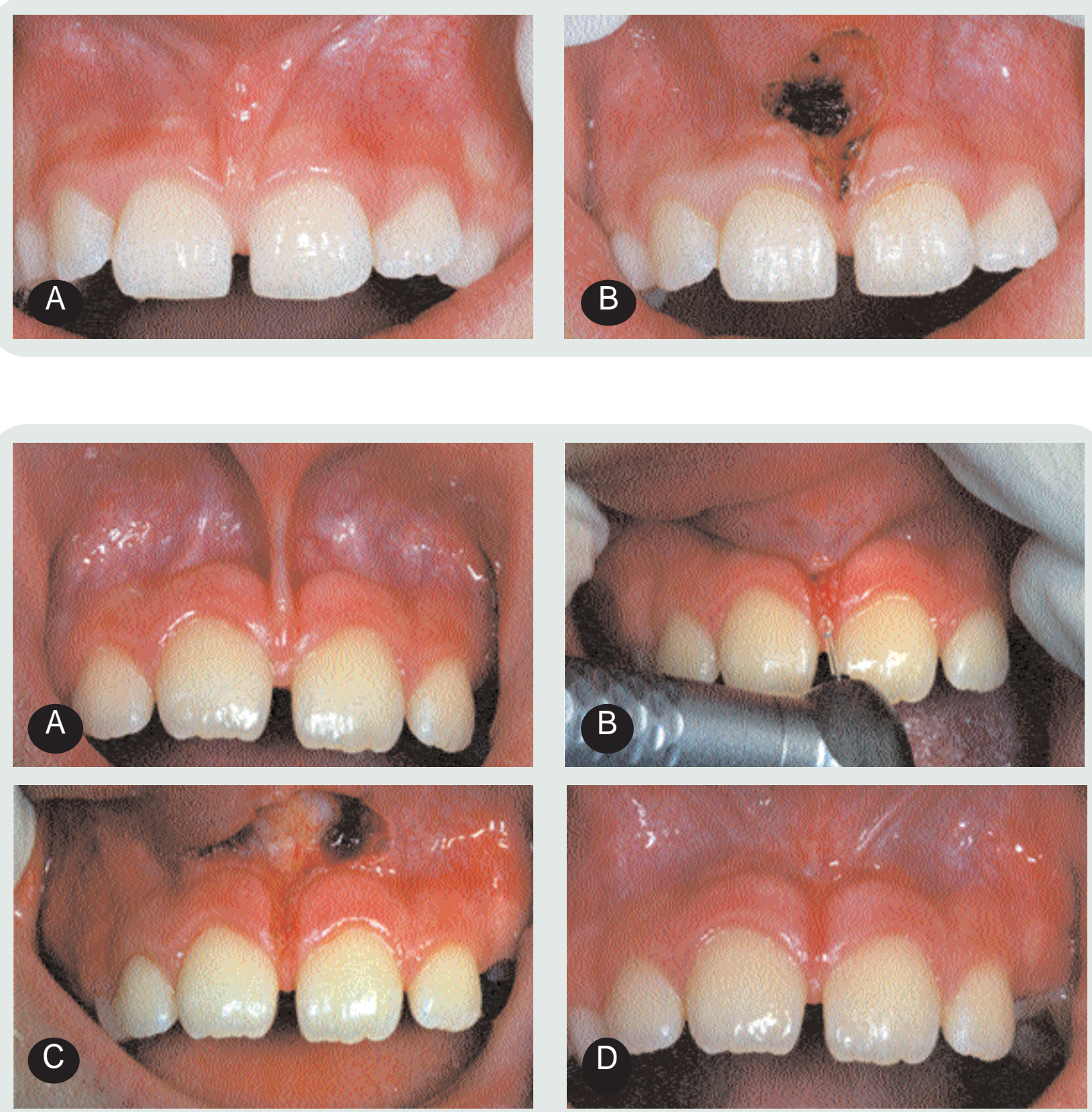

Figura 3. Frenectomía con láser de Er,Cr:YSGG. (A) Niña de 9 años de edad, remitida por su ortodoncista, que presentaba un frenillo labial superior hipertrófico con diastema interincisal y signo de la papila positivo. El tamaño y la movilidad del labio eran normales, por lo cual se optó por practicar una frenectomía simple, con láser. (B) Se infiltró, aproximadamente, la mitad de un cartucho de solución anestésica de articaína al 4\% con adrenalina al 1:200000, repartida entre el fondo vestibular de ambos lados y la papila interincisiva. Se utilizó el láser de Er,Cr:YSGG a 2,5W de potencia (20 hertzios) con spray de aire al 16\% y de agua al 8\%. (C) Se debe explorar la presencia de fibras en la sutura intermaxilar, y en el caso que existan, éstas deben ser eliminadas durante el acto operatorio. Cuando se ha completado la frenectomía no es necesario suturar la herida, dejando que ésta cicatrice por segunda intención. (D) El periodo postoperatorio cursó sin dolor ni edema. Esta imagen se obtuvo a las tres semanas de la intervención quirúrgica. 


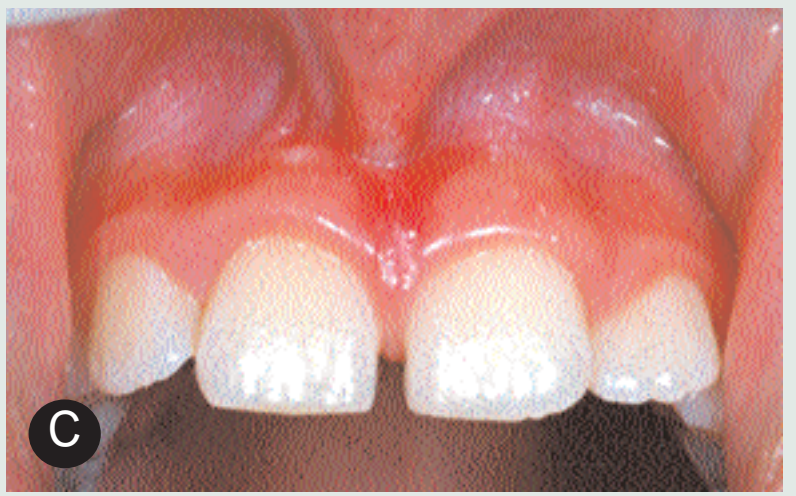

Figura 2. Frenectomía con láser de $\mathrm{CO}_{2}$. (A) Varón de 10 años de edad, sin antecedentes de interés, remitido por su ortodoncista para la frenectomía del frenillo labial superior. (B) Se infiltró medio cartucho de solución anestésica de articaína al 4\% con adrenalina al 1:200000, repartido por los zonas que iban a ser irradiadas. Se vaporizó el frenillo con un láser de $\mathrm{CO}_{2}$ a $5 \mathrm{~W}$ de potencia, en modo continuo, aplicando la energía de forma ligeramente desfocalizada. Esta imagen corresponde al postoperatorio inmedia-

to. (C) El postoperatorio cursó sin dolor ni edema. A las tres semanas de la frenectomía podemos apreciar la nueva inserción del frenillo, que siempre se sitúa en el límite entre la encía libre y la encía queratinizada.
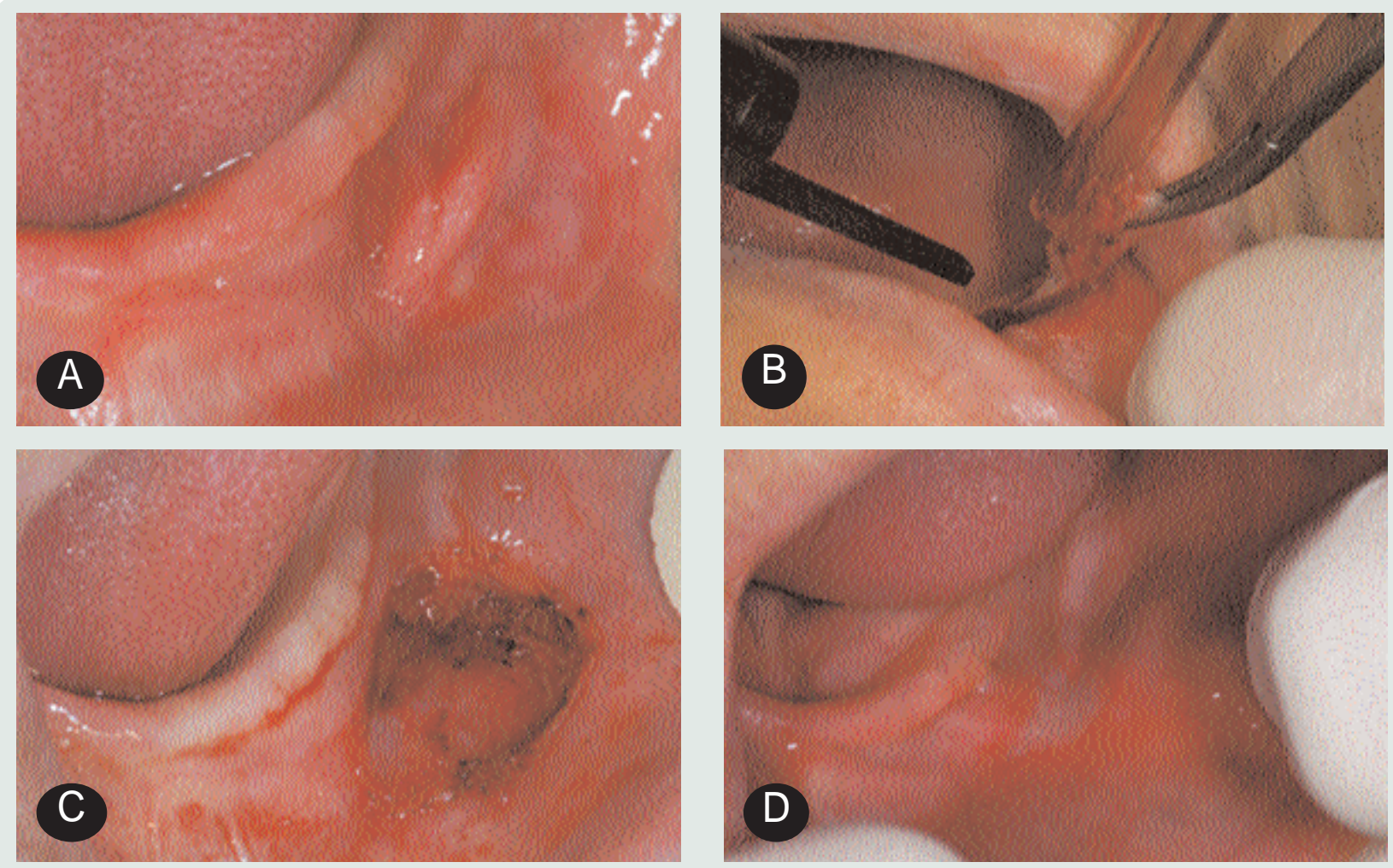

Figura 4. Épulis fisurado. (A) Mujer totalmente desdentada de 76 años de edad, que presentaba una lesión en el fondo del vestíbulo inferior izquierdo, que coincidía con la inserción de su prótesis completa, compatible con el diagnóstico clínico de épulis fisurado. (B) Se infiltró menos de $1 \mathrm{ml}$ de solución anestésica de articaína con 0,5 mg\% de epinefrina en el fondo vestibular, cerca del agujero mentoniano. Se utilizó el láser de CO2 de forma continua a $7 \mathrm{~W}$, trabajando de forma focalizada para conseguir efecto de corte. (C) Aspecto del postoperatorio inmediato. Es conveniente reformar la prótesis completa para evitar traumatizar la herida. Una vez retocada la resina que corresponde a la zona de la lesión, es aconsejable rellenar la prótesis con algún acondicionador de tejidos; de esta forma se consigue mejor ajuste de la misma. (D) Imagen obtenida a las tres semanas de la exéresis. El informe histopatológico fue de hiperplasia fibrosa, confirmando el diagnóstico clínico. La paciente no presentó ni dolor ni edema en el postoperatorio. 

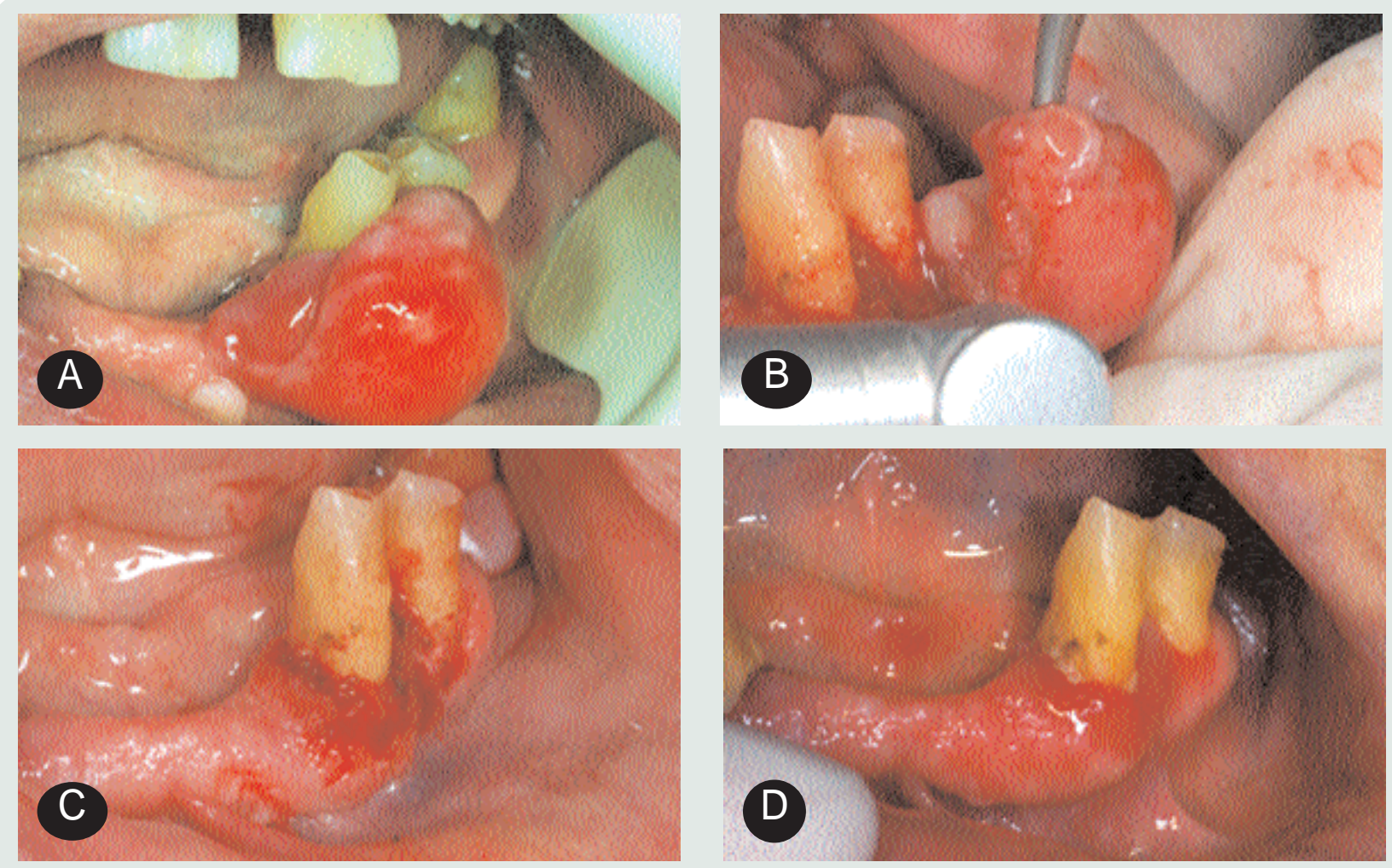

Figura 5. Épulis telangiectásico. (A) Mujer parcialmente desdentada de 68 años de edad, que presentaba dos lesiones en el cuadrante inferior izquierdo, una más blanquecina, cerca de la línea media de la mucosa queratinizada vestibular, redondeada, de $4 \mathrm{~mm}$ de diámetro, y otra de 1,5 cm de diámetro, pediculada y hemiesférica, con un aspecto eritematoso e inflamato-

rio, que rodeaba al 3.3, compatible con el diagnóstico clínico de épulis telangiectásico. La lesión de mayor tamaño había aparecido dos años antes, según relató la paciente. (B) Sin utilizar ningún tipo de solución anestésica, se procedió a la exéresis de ambas lesiones. Se utilizó el láser de Er,Cr:YSGG focalizado, a $2 \mathrm{~W}$ de potencia (pulsos de 100mj a 20 pulsos por segundo) con spray de aire al 16\% y de agua al 8\%. (C) Imagen del postoperatorio inmediato. (D) Aspecto a las cuatro semanas del tratamiento. El informe anatomopatológico fue de hiperplasia fibrosa en el caso de la lesión más pequeña, y de hiperplasia fibrosa combinada con angiofibroma para la lesión de mayor tamaño. La paciente no precisó tomar ningún tipo de medicación durante el postoperatorio.

Se ha propuesto el uso del láser de $\mathrm{Nd}$ :YAG para vitrificar la dentina de la zona de la apicectomía, previamente a la obturación retrógrada ${ }^{23}$. La confección de la caja de obturación retrógrada se efectúa habitualmente con puntas ultrasónicas.

Son muchas las situaciones clínicas que requieren la exéresis de un frenillo bucal, bien sea el labial superior, labial inferior o lingual. En el caso del frenillo labial superior, el clínico puede decidir su eliminación con el láser, siempre y cuando no exista un compromiso con el labio donde se inserta. En el caso de labios con aspecto hipoplásico o atrófico, labios «cortos» o en pacientes con sellado labial incompleto, se debe optar por la realización de otras técnicas, como la Z-plastia, para obtener así un aumento importante en la profundidad del fondo vestibular, que permita que las estructuras musculares adquieran una funcionalidad y aspecto normales. Cual- quiera de los láseres quirúrgicos citados anteriormente puede ser utilizado, si bien el que ofrece mayor rapidez $y$ mayor control del sangrado intraoperatorio es el de $\mathrm{CO}_{2}$ (fig. 2) Los láseres de Er,Cr:YSGG (fig. 3) y de Er:YAG obtienen, no obstante, cicatrizaciones más rápidas.

\section{Lesiones en tejidos blandos}

Los tejidos blandos que conforman la cavidad bucal pueden albergar distintos 

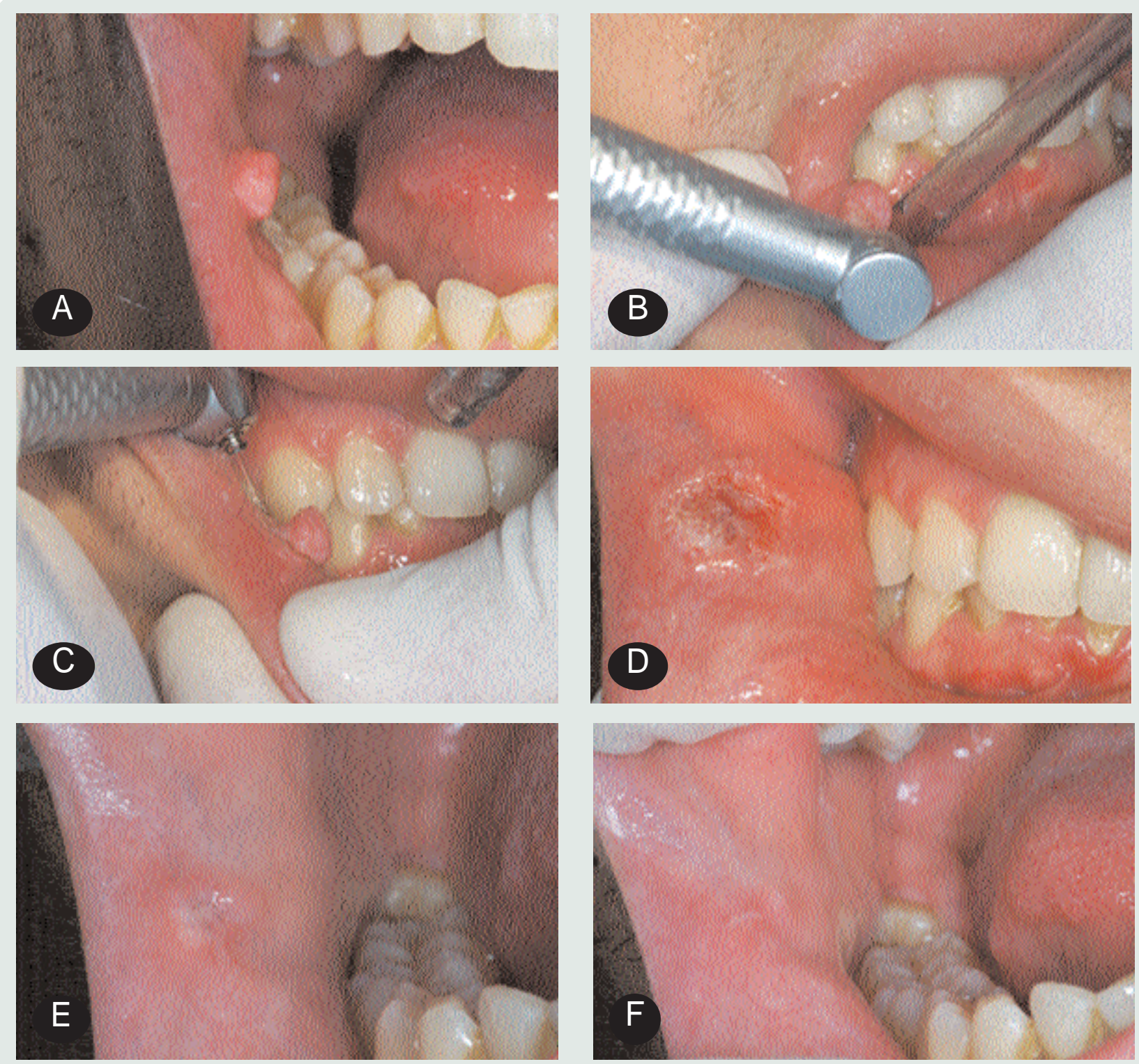

Figura 6. Fibroma. (A) Varón de 20 años de edad sin antecedentes patológicos de interés, remitido por presentar una lesión exofítica en la zona retrocomisural derecha de su mucosa yugal. (B) Se inició la exéresis sin administrar ningún tipo de técnica anestésica, con el láser de Er,Cr:YSGG focalizado, a 1,25W de potencia y con un 12\% de aire y un 8\% de agua. (C) Se irradió toda la base de la lesión hasta conseguir su escisión. (D) Se controló la hemostasia con la irradiación del mismo láser a $1 \mathrm{~W}$ de potencia, con un $6 \%$ de aire y un $4 \%$ de agua. La fotografía muestra el postoperatorio inmediato. No se prescribió ningún tipo de medicación. (E) Esta fotografía se tomó a la semana de la exéresis. (F) A las tres semanas la herida mostraba este aspecto. El paciente relató no haber tenido ningún tipo de molestia derivado de la intervención quirúrgica.

tipos de tumoraciones, con etiologías y características anatomopatológicas muy diversas. Si bien las más frecuentes sue- len corresponder a las hiperplasias fibrosas (figs, 4-6), también pueden verse, entre otras, lesiones relacionadas con el papilomavirus humano (PVH-1), donde el láser más aconsejado para su tratamiento es el de $\mathrm{CO}_{2}$. También podemos 

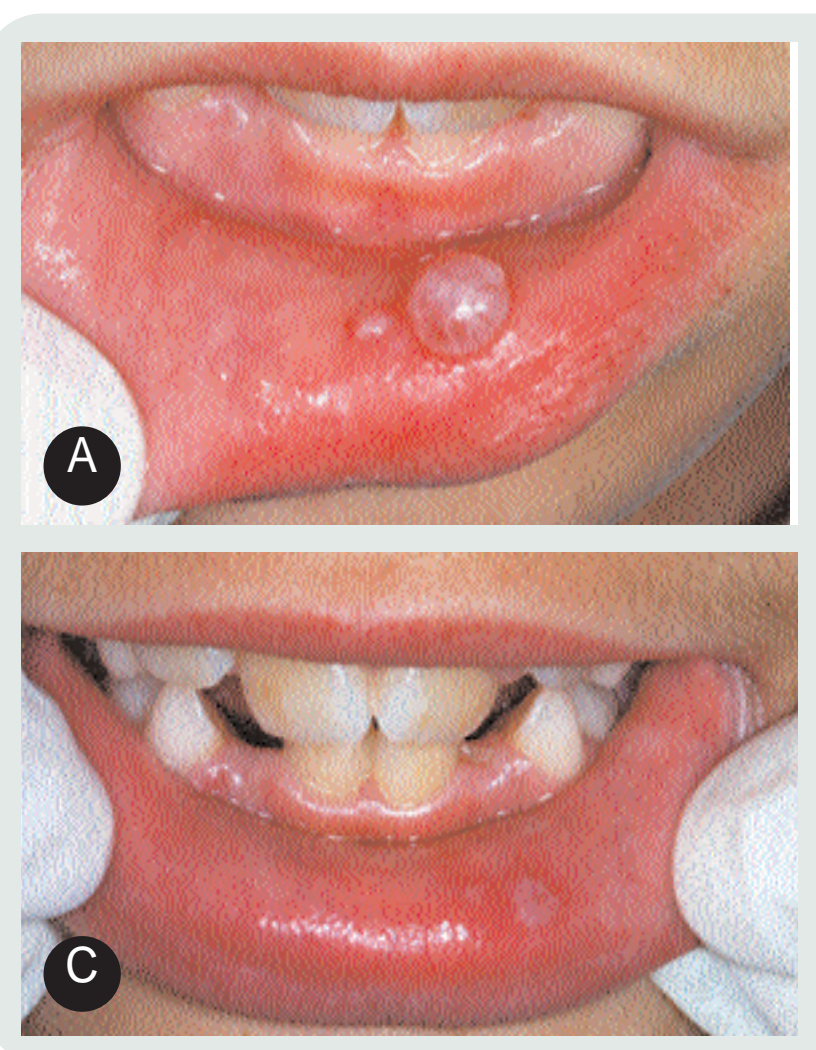

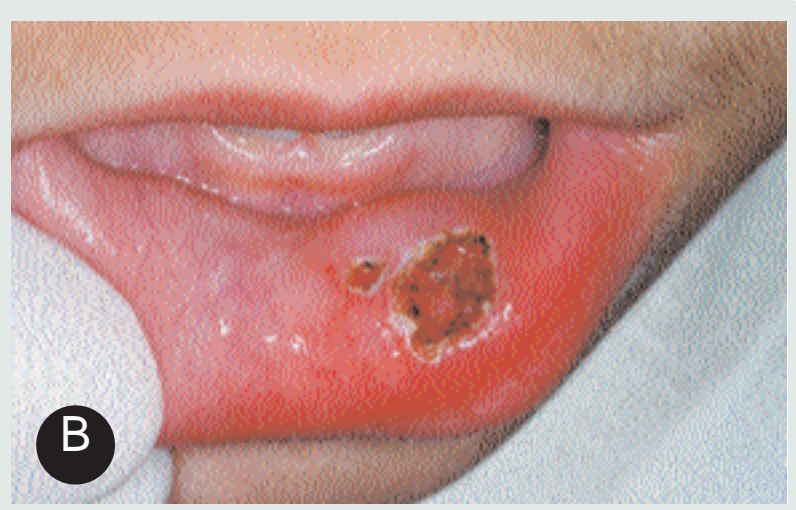

Figura 7. Mucocele. (A) Niña de 8 años de edad que presentaba dos lesiones en la cara interna de la mucosa labial inferior, compatibles con el diagnóstico de mucoceles por extravasación. Se administró 0,5 ml. de solución anestésica de articaína con 0,5 $\mathrm{mg} \%$ de epinefrina, infiltrada alrededor de la lesión. Se utilizó el láser de CO2 a 5W de potencia en modo continuo. (B) Aspecto que ofrecía en el postoperatorio inmediato. (C) Aspecto a las tres semanas del tra-

tamiento. El informe del anatomopatológo confirmó el diagnóstico. La paciente no presentó ningún tipo de molestia durante el postoperatorio. encontrarnos con lesiones de origen vascular, en las que podrían ser utilizados otros tipos de láseres como el de $\mathrm{Nd}$ :YAG.

La mayoría de las lesiones que se observan en la mucosa bucal suelen ser de tipo benigno, pero siempre es aconsejable efectuar el estudio histopatológico de las mismas, para tener un diagnóstico de certeza y así prevenir posibles complicaciones de todo tipo.

Cuando el clínico no tiene la absoluta seguridad en el diagnóstico preoperatorio de este tipo de lesiones, la utilización de algún tipo de láser que posea un marcado efecto térmico puede alterar gravemente la interpretación por parte del anatomopatólogo, de los bordes del tejido biopsiado. Por este motivo se aconseja utilizar láseres que no dificulten el estudio histológico de las muestras, como, por ejemplo, el láser de Er,Cr:YSGG o el láser de Er:YAG aplicados con spray de aire y agua.

Existen múltiples referencias bibliográficas del uso de diferentes tipos de láseres que se emplean con éxito en el tratamiento de exéresis de gran variedad de tumoraciones benignas de la cavidad bucal, como por ejemplo papilomas, granulomas, granulomas piógenos, ránulas, mucoceles (fig. 7), úlceras inflamatorias, fibromas, hiperplasia epitelial focal de la cavidad bucal, angiomas ${ }^{24}$, angiomas cavernosos, aftas recurrentes de la mucosa bucal, diapneusias, épulis, manchas melánicas, etc..$^{8^{* *}}$.

Con estos mismos criterios también pueden efectuarse tratamientos periodontales, tales como gingivectomías o gingivoplastias, $u$ otros tratamientos, como la eliminación de telangiectasias o de cualquier otra patología que afecte a los tejidos blandos bucales ${ }^{25^{*}, 26}$.

También se ha descrito su uso en la segunda cirugía de los tratamientos implantológicos, concretamente para eliminar el capuchón mucoso que separa el implante de la cavidad bucal ${ }^{27}$.

Por regla general, se trata de intervenciones quirúrgicas rápidas, sin necesidad de colocar puntos de sutura, exangües cuando se utilizan láseres con efecto térmico, con un curso postoperatorio libre de molestias para el paciente y con una reparación tisular de gran calidad estética.

Tampoco hay que olvidar el papel de los láseres de baja potencia (LLLT) indicados para el tratamiento de algias de etiología diversa y como bioestimulan$\mathrm{te}^{28}$. 


\section{Lesiones premalignas}

Existe una discusión permanente sobre la utilización de los distintos tipos de láseres en este tipo de lesiones. Nosotros aconsejamos que ante la sospecha de una lesión premaligna, previamente a su posible tratamiento con láser, se proceda de forma meticulosa a su estudio anatomopatológico.

Como principio general, en Cirugía Bucal es mejor extirpar una lesión que destruirla, especialmente cuando su naturaleza histológica no está clara. Pero cuando hay un crecimiento celular benigno en un lugar inaccesible, la vaporización es una alternativa aceptable. Cuando la lesión es maligna o se tenga algún dato que lo haga sospechar, no debe ser destruida sin haber obtenido antes muestras de tejido para el examen histopatológico, controlando los márgenes y la profundidad de la lesión.

El láser de $\mathrm{CO}_{2}$ se ha propuesto como método para evitar la difusión de bacterias o células tumorales al hacer una excisión, pues de igual modo que coagula los vasos sanguíneos con calibre inferior a los 0,5 mm de diámetro ${ }^{8 * *}$, es presumible que también coagule los vasos linfáticos. Kaminer y cols., en un estudio experimental sobre hámsters, no encontraron ninguna bacteriemia tras realizar incisiones en el abdomen con láser de $\mathrm{CO}_{2}$, frente a un $65 \%$ de bacteriemias con bisturí frío y un 90\% con electrocirugía ${ }^{29}$.

Los resultados más satisfactorios en el tratamiento de las lesiones premalignas se obtienen en las leucoplasias, siendo muy discutido su uso en el liquen plano y especialmente si se trata de un liquen plano erosivo ${ }^{8 * *}$.

En nuestra opinión, se puede hacer una biopsia excisional utilizando exclusi-

\section{Tabla 2. Tratamientos en Terapéutica dental}

\begin{tabular}{lccccc} 
Tratamiento / Láser & Diodo & Nd:YAG & Er,Cr:YSGG & Er:YAG & CO $_{2}$ \\
\hline Preparación de cavidades & 0 & 1 & 4 & 4 & 0 \\
\hline Eliminación de composites & 0 & 0 & 4 & 4 & 0 \\
\hline Grabado del esmalte & 0 & 1 & 4 & 4 & 2 \\
\hline Sellado de fosas y fisuras & 1 & 2 & 4 & 4 & 1 \\
\hline Hiperestesia dentinaria & 1 & 2 & 4 & 4 & 2 \\
\hline Endodoncia & 4 & 4 & 2 & 2 & 1 \\
\hline Carillas estéticas & 0 & 0 & 4 & 4 & 0 \\
\hline Blanqueamiento dental & 4 & (KTP) 4 & 0 & 0 & 1 \\
\hline Preparación de coronas & 0 & 0 & 3 & 3 & 0 \\
\hline Criterios de valoración: $0=$ Contraindicado. $1=$ Se puede utilizar. 2=Indicado. 3=Bastante indicado. \\
4=Muy indicado.
\end{tabular}

vamente el láser de $\mathrm{CO}_{2}$, una vez diagnosticada previamente la naturaleza de la lesión con biopsias incisionales, con un control muy meticuloso de los márgenes $^{8+*}$. Si bien técnicamente puede resultar complicado, creemos que puede disminuir las recidivas, así como el riesgo de diseminación, y por otra parte nos aseguramos un postoperatorio confortable para nuestros pacientes. En este aspecto Roodenburg y cols revisaron los resultados del tratamiento con láser de $\mathrm{CO}_{2}$ aplicado en 70 pacientes con 103 leucoplasias en la cavidad bucal. Tras un seguimiento medio de 5,3 años, el índice de curación fue del $90 \%$, considerado por los autores alto en comparación con otros estudios en los que la resección de la lesión se hizo con bisturí convencional o con criocirugía. Como ventajas del láser de $\mathrm{CO}_{2}$ frente a otros tipos de tratamiento se destacó la posibilidad de aplicar la tecnología láser con un microscopio quirúrgico, lo que permite mayor precisión, minimiza las lesiones que se producen en los tejidos adyacentes, y explica el excelente postoperatorio que suelen presentar los pacientes y la buena cicatrización de las heridas, que permite conservar la funcionalidad de los tejidos donde se asentaba la lesión. Como desventaja de esta técnica apuntan que, al destruir los márgenes de los tejidos tomados para la biopsia, la muestra puede resultar pequeña, lo que nos obliga a implementar un seguimiento postoperatorio muy riguroso ${ }^{30}$.

En nuestro criterio, aunque éste es un tema bastante controvertido en la literatura, sólo aconsejamos la utilización del láser de $\mathrm{CO}_{2}$ para vaporizar lesiones premalignas en régimen ambulatorio, en aquellos casos en que se dispone previamente de información histopatológica de la lesión, y siempre y cuando el informe del anatomopatólogo no revele más que una displasia leve o moderada $^{8 * t}$.

En los casos donde se diagnostique en una biopsia previa la presencia de una displasia severa, ante el riesgo de que puedan coexistir en la misma lesión otros aspectos más graves, aconsejamos recurrir a las técnicas quirúrgicas convencionales con las que se tiene 
una amplia experiencia clínica.

\section{Indicaciones}

\section{$y$ \\ contraindica- \\ ciones del \\ uso de dife- \\ rentes tipos de láseres}

Para terminar presentamos, en las tablas 2 y 3 , un resumen de las indicaciones y contraindicaciones del uso de diferentes láseres en distintos tratamientos. En la tabla 2 se recogen algunos tratamientos sobre tejidos duros dentarios, concernientes a terapéutica dental, y en la tabla 3 se muestran diferentes procedimientos y patologías del ámbito de la Cirugía Bucal. Esta valoración está basada en la experiencia de los autores y por tanto sólo tiene carácter orientativo.
Tabla 3. Tratamientos y patologías en el ámbito de la Cirugía bucal

\begin{tabular}{|c|c|c|c|c|c|}
\hline Tratamiento / Láser & Diodo & Nd:YAG & Er,Cr:YSGG & Er:YAG & $\mathrm{CO}_{2}$ \\
\hline Frenillo labial superior & 2 & 1 & 3 & 3 & 4 \\
\hline Frenillo labial inferior & 2 & 1 & 3 & 3 & 4 \\
\hline Frenillo lingual & 2 & 1 & 3 & 3 & 4 \\
\hline Pigmentaciones & 3 & 3 & 2 & 2 & 3 \\
\hline Papilomas de origen vírico & 1 & 1 & 0 & 0 & 4 \\
\hline Papilomas de origen no vírico & 2 & 2 & 3 & 3 & 4 \\
\hline Fibromas & 2 & 1 & 4 & 4 & 4 \\
\hline Diapneusias & 2 & 1 & 4 & 4 & 4 \\
\hline Mucoceles & 2 & 1 & 3 & 3 & 4 \\
\hline Angiofibromas & 3 & 2 & 3 & 3 & 4 \\
\hline Hiperplasias fibrosas & 2 & 1 & 3 & 3 & 4 \\
\hline Épulis telangiectásico & 3 & 2 & 3 & 3 & 4 \\
\hline Épulis fibroso & 2 & 1 & 3 & 3 & 4 \\
\hline Épulis gravídico & 3 & 2 & 3 & 3 & 4 \\
\hline $\begin{array}{l}\text { Granuloma periférico de } \\
\text { células gigantes }\end{array}$ & 2 & 1 & 3 & 3 & 4 \\
\hline Granuloma piógeno & 2 & 1 & 3 & 3 & 4 \\
\hline Épulis fisurado & 2 & 1 & 3 & 3 & 4 \\
\hline Gingivectomías & 1 & 0 & 2 & 2 & 2 \\
\hline $\begin{array}{l}\text { Eliminación de tejido } \\
\text { de granulación }\end{array}$ & 1 & 1 & 3 & 3 & 4 \\
\hline Alargamiento de coronas & 1 & 0 & 3 & 3 & 3 \\
\hline Vestíbuloplastia con injerto & 0 & 0 & 3 & 4 & 0 \\
\hline $\begin{array}{l}\text { Vestíbuloplastia por } \\
2^{\mathrm{a}} \text { intención }\end{array}$ & 1 & 1 & 3 & 3 & 4 \\
\hline $\begin{array}{l}\text { Eliminación de bridas y } \\
\text { frenillos }\end{array}$ & 2 & 1 & 3 & 3 & 4 \\
\hline $\begin{array}{l}\text { Exostosis y torus mandi- } \\
\text { bulares o palatinos }\end{array}$ & 0 & 0 & 4 & 4 & 0 \\
\hline Angiomas (con cirugía & & & & & \\
\hline convencional) & 3 & 4 & 0 & 0 & 2 \\
\hline $\begin{array}{l}\text { Angiomas sólo láser } \\
\text { (descartar shunt) }\end{array}$ & 3 & 4 & 0 & 0 & 3 \\
\hline $\begin{array}{l}\text { Periodoncia; Eliminación } \\
\text { de cálculo }\end{array}$ & 0 & 0 & 3 & 3 & 0 \\
\hline $\begin{array}{l}\text { Periodoncia: Descontami- } \\
\text { nación de bolsas }\end{array}$ & 4 & 4 & 3 & 3 & 2 \\
\hline $\begin{array}{l}\text { Cirugía periapical: Legrado } \\
\text { apical }\end{array}$ & 1 & 1 & 3 & 3 & 3 \\
\hline Cirugía periapical: Ostectomía & 0 & 0 & 4 & 4 & 0 \\
\hline Cirugía periapical: Curetaje & 2 & 2 & 3 & 3 & 2 \\
\hline Cirugía periapical: & & & & & \\
\hline Apicectomía & 0 & 0 & 4 & 4 & 0 \\
\hline $\begin{array}{l}\text { Cirugía periapical: Cavidad } \\
\text { retrógrada }\end{array}$ & 0 & 0 & 0 & 0 & 0 \\
\hline Implantología: Segundas fases & 3 & 1 & 4 & 4 & 4 \\
\hline Mucositis periimplantaria & 3 & 3 & 4 & 4 & 3 \\
\hline Fenestraciones: Ostectomía & 0 & 0 & 4 & 4 & 0 \\
\hline Dientes incluidos: Ostectomía & 0 & 0 & 4 & 4 & 0 \\
\hline $\begin{array}{l}\text { Dientes incluidos: Odonto- } \\
\text { sección }\end{array}$ & 0 & 0 & 4 & 4 & 0 \\
\hline $\begin{array}{l}\text { Lesiones premalignas:leuco- } \\
\text { plasias sin displasia. Informe } \\
\text { Anatomopatológico previo }\end{array}$ & 1 & 1 & 3 & 3 & 4 \\
\hline
\end{tabular}




\section{Bibliografía recomendada}

Para profundizar en la lectura de este tema, el/los autor/es considera/an interesantes los artículos que aparecen señalados del siguiente modo: *de interés **de especial interés.

1. Kinoshita J, Kimura Y, Matsumoto K. Comparative study of carious dentin removal by Er,Cr:YSGG laser and Carisolv. J Clin Laser Med Surg 2003;21:307-15.

2. Attrill DC, Davies RM, King TA, Dickinson MR, Blinkhorn AS. Thermal effects of the Er:YAG laser on a simulated dental pulp: A quantitative evaluation of the effects of a water spray. J Dent 2004;32:35-40.

3. Cavalcanti BN, Lage-Marques JL, Rode SM. Pulpal temperature increases with Er:YAG laser and high-speed handpieces. J Prosthet Dent 2003;90:447-51.

4. Lee BS, Hsieh TT, Lee YL, Lan WH, Hsu YJ, Wen $\mathrm{PH}$, Lin CP. Bond strengths of orthodontic bracket after acid-etched, Er:YAG laser-irradiated and combined treatment on enamel surface. Angle Orthod 2003;73:56570.

5. Usumez S, Orhan M, Usumez A. Laser etching of enamel for direct bonding with an Er,Cr:YSGG hydrokinetic laser system. Am J Orthod Dentofacial Orthop 2002;122:64956.

6. * Keller U, Hibst R, Geurtsen W, Schilke R, Heidemann D, Klaiber B, Raab WH. Erbium:YAG laser application in caries therapy. Evaluation of patient perception and acceptance. J Dent 1998;26:649-56.

Este artículo evalúa las sensaciones que los pacientes refieren durante el tratamiento de una caries utilizando el láser de Er:YAG. Los pacientes tratados prefieren el uso del láser frente al tratamiento convencional.

7. Jacboson B, Berger J, Kravitz R, Ko J. Laser pediatric Class II composites utilizing no anesthesia. J Clin Pediatr Dent 2004;28:99101.

8.** España Tost A, Velasco Vivancos V, Gay Escoda C, Berini Aytés L, Arnabat Domínguez J. Aplicaciones del láser de $\mathrm{CO}_{2}$ en Odontología. Madrid: Ergon;1995.

Libro centrado en las aplicaciones del láser de CO2 en Odontología, destacando especialmente las referidas a la Cirugía Bucal.

9. Apel C, Schafer C, Gutknecht N. Demineralization of Er:YAG and Er,Cr:YSGG laserprepared enamel cavities in vitro. Caries Res 2003;37:34-7.
10. Shigetani $Y$, Tate $Y$, Okamoto A, Iwaku M, Abu-Bakr N. A study of cavity preparation by Er:YAG laser. Effects on the marginal leakage of composite resin restoration. Dent Mater J 2002;21:238-49.

11. Ceballos L, Camejo DG, Victoria Fuentes M $y$ cols. Microtensile bond strength of totaletch and self-etching adhesives to cariesaffected dentine. J Dent 2003;31:469-77.

12. Kato J, Moriya K, Jayawardena JA, Wijeyeweera RL, Awazu K. Prevention of dental caries in partially erupted permanent teeth with a $\mathrm{CO}_{2}$ laser. J Clin Laser Med Surg 2003;21:369-74.

13. Chen WH. Laser root canal therapy. J Indiana Dent Assoc 2002;81:20-3.

14. Brugnera A, Jr., Zanin F, Barbin EL, Spano JC, Santana R, Pecora JD. Effects of Er:YAG and Nd:YAG laser irradiation on radicular dentine permeability using different irrigating solutions. Lasers Surg Med 2003;33:256-9.

15. Kreisler M, Kohnen W, Beck M y cols. Efficacy of $\mathrm{NaOCl} / \mathrm{H}_{2} \mathrm{O}_{2}$ irrigation and GaAlAs laser in decontamination of root canals in vitro. Lasers Surg Med 2003;32:189-96.

16. Pearson GJ, Schuckert KH. The role of lasers in dentistry: Present and future. Dent Update 2003;30:70-4,76.

17. Usumez A, Aykent F. Bond strengths of porcelain laminate veneers to tooth surfaces prepared with acid and Er,Cr:YSGG laser etching. J Prosthet Dent 2003;90:24-30.

18. Jones AH, Diaz-Arnold AM, Vargas MA, Cobb DS. Colorimetric assessment of laser and home bleaching techniques. J Esthet Dent 1999;11:87-94.

19. Jacboson B, Berger J, Kravitz R, Patel P. Laser pediatric crowns performed without anesthesia: A contemporary technique. J Clin Pediatr Dent 2003;28:11-2.

20. Wang $X$, Ishizaki NT, Suzuki N, Kimura $Y$, Matsumoto K. Morphological changes of bovine mandibular bone irradiated by Er,Cr:YSGG laser: An in vitro study. J Clin Laser Med Surg 2002;20:245-50.

21. Kimura $Y$, Yu DG, Fujita A, Yamashita A, Murakami $Y$, Matsumoto $K$. Effects of erbium,chromium:YSGG laser irradiation on canine mandibular bone. $\mathrm{J}$ Periodontol
2001;72: 1178-82.

22. Gouw-Soares S, Tanji E, Haypek P, Cardoso W, Eduardo CP. The use of Er:YAG Nd:YAG and Ga-Al-As lasers in periapical surgery: A 3-year clinical study. J Clin Laser Med Surg 2001;19:193-8.

23. Arisu HD, Bala O, Alimzhanova G, Turkoz $E$. Assessment of morphological changes and permeability of apical dentin surfaces induced by Nd:Yag laser irradiation through retrograde cavity surfaces. J Contemp Dent Pract 2004;5:102-13.

24. España Tost A, Velasco Vivancos V, Berini Aytés L, Gay Escoda C. Tratamiento de los angiomas bucales con láser de $\mathrm{CO}_{2}$. $\mathrm{Rev}$ Actual Odontoestomatol Esp 1994;43:34-8.

25.* Ishikawa I, Aoki A, Takasaki AA. Potential applications of Erbium:YAG laser in periodontics. J Periodontal Res 2004;39:275-85. Interesante artículo donde se comentan las aplicaciones del láser de Er:YAG para distintos tratamientos periodontales.

26. Miyazaki A, Yamaguchi T, Nishikata J y cols. Effects of Nd:YAG and $\mathrm{CO}_{2}$ laser treatment and ultrasonic scaling on periodontal pockets of chronic periodontitis patients. J Periodontol 2003;74:175-80.

27. Arnabat-Dominguez J, España-Tost AJ, Berini-Aytés L, Gay-Escoda C. Erbium:YAG laser application in the second phase of implant surgery: A pilot study in $\mathbf{2 0}$ patients. Int J Oral Maxillofac Implants 2003;18:104-12.

28. Pinheiro AL, Cavalcanti ET, Pinheiro TI y cols. Low-level laser therapy is an important tool to treat disorders of the maxillofacial region. J Clin Laser Med Surg 1998;16:2236.

29. Kaminer R, Liebow C, Margarone JE, 3rd, Zambon JJ. Bacteremia following laser and conventional surgery in hamsters. J Oral Maxillofac Surg 1990;48:45-8.

30. Roodenburg JL, Panders AK, Vermey A. Carbon dioxide laser surgery of oral leukoplakia. Oral Surg Oral Med Oral Pathol 1991;71:670-4. 